\title{
A study of the potential effect of Depression on Male Sexual Functioning
}

\author{
Vinay Kumar ${ }^{1}$, Bhagyashri Balajirao Shinde ${ }^{2}$ \\ ${ }^{1}$ Assistant Professor, Department of Psychiatry, Navodaya Medical College Hospital \& Research Centre, \\ Raichur \\ ${ }^{2}$ Duty Doctor, Manasvi Hospital, Raichur \\ Corresponding author: Vinay Kumar \\ Email - drvinaykumarmd@gmail.com
}

\begin{abstract}
Background: The relationship between major depressive disorder (MDD) and sexual dysfunction is complex. Sexual symptoms in depression often include decreased libido, erectile dysfunction, ejaculatory delay, decreased sexual satisfaction and decreased pleasure. Men with depression had 1.8 times higher chance of experiencing erectile dysfunction than those without depression, and the prevalence rates of erectile dysfunction increased as the severity of depression increased. The aim is to study the potential effect of depression on male sexual functioning.

Methodology: Written and informed consent was taken from all the patients and control individuals and assessment of sexual functioning with International Index of Erectile Function (IIEF) and Change in Sexual Functioning Questionnaire (CSFQ-14) scales was done. 1) Study Group: 30 married men diagnosed with Major Depressive Disorder (MDD), aged 21-50 years, attending psychiatry department in Navodaya Medical College Hospital \& Research Centre, Raichur, India, have been recruited, irrespective of their region, religion, caste, sub-caste etc. 2) Control Group: 30 married and healthy men, aged 21-50 years, with no history of psychiatric disorder, have been taken irrespective of their region, religion, caste, sub-caste etc. Results: Socio-demographic variables in control and depression group revealed no differences in age distribution, education, occupation, domicile and religion. Both IIEF and CSFQ-14 scales showed statistically significant results $(p<0.0001)$ in the depression group.

Conclusion: Depression has an impact on male sexual functioning which is consistent with previous studies. The erectile function, orgasmic function, sexual desire, intercourse satisfaction and overall satisfaction are significantly disturbed in depressed individuals when compared with control individuals.
\end{abstract}

Keywords: Depression, male sexual dysfunction, sexual medicine, erectile function, IIEF

(Paper received $-15^{\text {th }}$ February 2020, Peer review completed $-28^{\text {th }}$ February 2020)

(Accepted $-28^{\text {th }}$ February 2020)

\section{INTRODUCTION}

Adequate sexual expression is an essential part of many human relationships that enhances the quality of life providing a sense of physical, psychological and social well-being. Normal sexual function is a biopsychosocial process. Sexual dysfunction commonly drives from biological, psychological, or social arena, but virtually always affects all three. In clinical practice, the most commonly encountered male sexual dysfunctions are hypo sexual desire disorder, premature ejaculation, and erectile dysfunction. The change in sexual function with age is multi factorial and variable. Important co-factors include availability and health of a partner, relationship dynamics, fear of performance failure, chronic illness, substance and medication use, neuropathy, vascular insufficiency and depression [1]. 
Sexual functioning is a complex process, and sexual dysfunction can occur during any of the stages of sexual response. Although the causal relationship between sexual dysfunction and depressive illness is unknown, these conditions are highly co-morbid. Sexual symptoms are prominent in major depression, and often include decreased libido, erectile dysfunction, ejaculatory delay, decreased sexual satisfaction and decreased pleasure [2]. The relationship between erectile dysfunction and depression is complex, and the causal relationship is not clear. The stress and anxiety that accompany erectile dysfunction may cause secondary depression, or erectile dysfunction can be one of the symptoms of major depressive disorder (MDD), or both conditions can coexist in a related or unrelated fashion [3]. In a subgroup of men with MDD, a reversible loss of nocturnal penile tumescence was reported, further suggesting that depression can directly affect erectile function. In the Massachusetts Male Aging Study (MMAS), men with depression had 1.8 times higher chance of experiencing erectile dysfunction than those without depression, and the prevalence rates of erectile dysfunction increased as the severity of depression increased [4].

\section{Sexual Dysfunction in Depressed Patients}

Depression is characterized by loss of interest, reduction in energy, lowered self-esteem and inability to experience pleasure: irritability and social withdrawal may impair the ability to form and maintain intimate relationships. This constellation of symptoms may be expected to produce difficulties in sexual relationships, and depression has long been associated with sexual problems [5]. In 132 patients with depressive disorders, loss of sexual interest, characterized by loss of libido or decrease of sexual desire or potency, was reported by $72 \%$ of patients with unipolar depression, and $77 \%$ of patients with bipolar depression [6]. Conversely, loss of sexual desire may be the presenting complaint of some patients, who only after direct questioning are found to have significant depressive symptoms. In others, low sexual desire may precede the onset of depression [7]. Comparative studies reveal higher levels of sexual dysfunction in depressed patients than in non-depressed controls. The specific type of sexual dysfunctions vary in incidence, but loss of sexual desire may be more common than disorders of arousal and orgasm: in a comparative study, changes in libido were significantly more common in depressed patients than controls, but differences in the prevalence of impotence, orgasmic or ejaculatory problems were not [8]. The prospective Zurich cohort study shows that the prevalence of sexual problems in depressed subjects (including those with major depression, dysthymia and recurrent brief depression) is approximately twice that in controls ( $50 \%$ versus $24 \%)$. This difference encompassed emotional problems, sexual dysfunction, and both decreased and increased libido. The data in the above study are from a group of young people (28-35 years) and may not be applicable to older age groups [9].

Although co morbidity between ED and depressive illness is apparently high, the causal relationship is unclear. ED and the psychosocial distress that often accompanies it may trigger the development of depressive illness in vulnerable individuals; depression may induce ED (a subgroup of men with MDD develop a reversible loss of nocturnal penile tumescence while depressed);[10-11] a third factor, such as substance abuse or medical illness, may cause both conditions; or these conditions may be etiologically unrelated and are co morbid simply because of their high prevalence, particularly in older men [12-13].

\section{Erectile Function in Men with Major Depressive Disorder}

Loss of libido is a classic symptom of melancholic MDD and has played a prominent role in psychodynamic and other anecdotal descriptions of depressive illness. Systematically collected data confirm that MDD is frequently associated with decreased libido, diminished erectile function, and decreased sexual activity [1011]. In some men, the presence of MDD is associated with a reversible impairment in sexual neurophysiology, leading to ED. Steiger and others [14] assessed several parameters of nocturnal penile tumescence (NPT) in 25 men with an acute episode of depression compared with non-depressed control subjects. Although no statistically significant differences in NPT parameters were found between the depressed group and the control subjects, there was a complete lack of NPT in four of 25 depressed men that was reversed after antidepressant therapy. In contrast, research has demonstrated a significant reduction in NPT time and decreased penile rigidity in 34 depressed men compared with nondepressed control subjects. NPT time was reduced by at least one standard deviation below the control mean in $40 \%$ of depressed men and was comparable to that in a group of 14 nondepressed men with a diagnosis of ED due to organic causes. 
These findings were confirmed in a repeat study with a new group of 51 men with major depression. Together, the results of these studies support the conclusion that erectile function as assessed by NPT is impaired or absent in some, but not all, depressed men, suggesting a neurophysiologic link between depression and ED [11].

\section{Depressive Symptoms among Men with Erectile Dysfunction}

The link between ED and depression among men who present with ED has not been systematically studied in clinical settings. There is, however, suggestive evidence from a large epidemiologic sample as well as from a sexual dysfunction clinic. The Massachusetts Male Aging Study was a cross-sectional, community-based random-sample survey of health and aging in men aged 40 to 70 years. It was conducted in 11 randomly selected towns in the Boston area between 1987 and 1989, and had a response rate of $76 \%(n=1290)$. Based on the subjects' responses to nine questions that were highly correlated with biologic measures of erectile response, levels of ED were graded as nil (48\%), minimal (17\%), moderate (25\%), or complete (10\%) [15]. Depression and anger were highly correlated with ED. Using the Centre for Epidemiologic Studies Depression Scale cut-off of 16 (which is correlated with MDD), all men with this degree of depressive symptomatology had some (i.e., minimal, moderate, or complete) ED [16]. Maximal level of anger (either suppression or expression, as defined by Spielberger's anger scales) was associated with approximately $75 \%$ overall ED, double the ED prevalence among men who reported minimal anger [15]. Two large studies describing psychiatric diagnoses and symptoms among men presenting to the Johns Hopkins Sexual Behaviours Consultation Unit from 1976 to $1979(n=199)$ and from 1984 to $1986(n=223)$ revealed that approximately one third had a comorbid psychiatric diagnosis (mostly affective, anxiety, or personality disorders) [17-18]. Men with ED had high levels of depressive, somatic, and anxious symptoms and scored very high on measures of overall psychological distress (using one well-validated instrument that measures such distress, these men scored in the 92nd percentile of the normative population). Finally, multiple studies have demonstrated a strong positive correlation between ED and reduced quality of life, impaired social and occupational functioning, and substance abuse [19].

The aim of this study was to look at the effect of depression on male sexual functioning.

\section{METHODOLOGY}

\section{Source and Methods of Data Collection}

\section{Study Subjects}

- 30 married men diagnosed with Major Depressive Disorder (MDD), aged 21-50 years, attending psychiatry department in Navodaya Medical College Hospital \& Research Centre, Raichur, India, have been recruited, irrespective of their region, religion, caste, sub-caste etc.

- The same 30 men were assessed using International Index of Erectile Function (IIEF) and Changes in Sexual Functioning Questionnaire (CSFQ-14) scales.

\section{Control Individuals}

- 30 married and healthy men, aged 21-50 years, with good physical and mental health, with no family history of psychiatric disorder, have been taken irrespective of their region, religion, caste, sub- caste etc.

- The same 30 men have been taken for sexual function using the International Index of Erectile Function (IIEF) and Changes in Sexual Functioning Questionnaire (CSFQ-14) scales.

Valid written and informed consent have been obtained from all the patients and healthy individuals under the study before assessing sexual functioning with IIEF and CSFQ-14 scales.

The sample size for the present study was 30 in each category.

\section{Inclusion criteria \\ Study Subjects}

1. Married men, staying with wife for at least one year, without undergoing permanent sterilization.

2. Diagnosed with Major Depressive Disorder (MDD) according to Diagnostic and Statistical Manual of Psychiatric Disorders (DSM-IV TR) criteria. 
3. Age: 21-50 years.

\section{Control Individuals}

1. Married and healthy men, with good physical and mental health.

2. Age: 21-50 years.

3. No family history of psychiatric disorder.

\section{Exclusion criteria}

\section{Study Subjects}

1. Unmarried men or married men with permanent sterilization.

2. Men diagnosed with Diabetes Mellitus, Hypertension, Substance dependence or any other psychiatric disorders.

3. Age: $<21$ years and $>50$ years.

\section{Control Individuals}

1. Unmarried men or married men with Diabetes Mellitus, Hypertension, Substance dependence or any other psychiatric disorders.

2. Age: $<21$ years and $>50$ years.

3. Family history of psychiatric disorder.

\section{Scales for assessing sexual functioning}

1. IIEF: The 15-question International Index of Erectile Function (IIEF) Questionnaire is a validated, multidimensional, self-administered investigation that has been found useful in the clinical assessment of erectile dysfunction and treatment outcomes in clinical trials. A score of 0-5 is awarded to each of the 15 questions that examine the 4 main domains of male sexual function: erectile function, orgasmic function, sexual desire and intercourse satisfaction [20-21].

- Erectile Function $(\mathrm{Q} 1,2,3,4,5,15)$

- Orgasmic Function $(\mathrm{Q} 9,10)$

- Sexual Desire $(\mathrm{Q} 11,12)$

- Intercourse Satisfaction $(\mathrm{Q} 6,7,8)$

- Overall Satisfaction $(\mathrm{Q} 13,14)$

2. CSFQ-14-MALE: The Changes in Sexual Functioning Questionnaire (CSFQ-14) uses 5-point Likert scales to provide the patient an opportunity to self-evaluate his or her sexual behaviours or problems in a number of areas. For all items, higher scores reflect higher sexual functioning. For 12 of the 14 items, higher sexual functioning corresponds to greater frequency or enjoyment/pleasure (e.g., $1=$ never to $5=$ every day). For two items (item 10, assessing loss of interest after arousal for women and priapism for men, and item 14, assessing painful orgasm), higher sexual functioning corresponds to lower frequency (e.g., $1=$ every day to $5=$ never). Items 10 and 14 are included in the total score but not in any scale score. In addition to providing a total sexual functioning score, the CSFQ-14 allows the possibility of eight scale scores, using two separate schemas: five scales corresponding to the scales on the original form of the CSFQ or three scales corresponding to the phases of the sexual response cycle [22-23].

The five original scales include:

- Desire/Frequency, a 2-item scale that assesses frequency of sexual acts, including intercourse and masturbation, and the frequency of desire to participate in sexual activity.

- Desire/Interest, a 3-item scale that assesses interest in and desire for sexual experiences as expressed in the frequency of sexual thoughts or fantasies and feelings of enjoyment elicited by erotica.

- Arousal/Excitement, a 3-item scale that assesses frequency of arousal, ease of arousal, and adequate vaginal lubrication/ erection during sexual activity. 
- Orgasm/Completion, a 3 item scale that assesses one's ability to achieve orgasm, including frequency of orgasms, ability to achieve orgasms when desired, and the degree of pleasure derived from orgasm.

- Pleasure, a single item that assesses current enjoyment of sex life in comparison with past enjoyment.

\section{STATISTICAL ANALYSIS}

Descriptive analysis was done by calculating mean, Standard Deviation, proportions. 95\% confidence interval of Mean is also calculated. Inferential statistics was done by chi-square test, independent $t$ test, Wilcoxon test, paired t test. $\mathrm{P}<0.05$ is considered statistically significant. All calculations were done by SPSS version 13.0.

\section{RESULTS}

\section{Socio-demographic variables \\ Age Distribution}

A total of 30 patients of depression (case) and 30 normal healthy individuals (control) were included in the study, attending psychiatry department in Navodaya Medical College Hospital \& Research Centre, Raichur, India. Out of 30 patients and 30 control, 17 patients (56.7\%) and 14 controls (46.7\%) are less than 30 years of age. 11 patients $(36.7 \%)$ and 13 control (43.3\%) are in the age group 31-40 years, and 2 patients $(6.7 \%)$ and 3 controls $(10 \%)$ are more than 40 years $(p=0.9)$. Statistically data is not significant. Minimum age of the patients in my study is 22 years and maximum is 50 years. Mean age is 36 years. The difference between cases and controls were statistically insignificant.

\section{Education}

Among 30 patients, 10 patients (33.3\%) have an education level above high school but not graduated, 9 patients $(30 \%)$ have primary education. Only 3 patients $(10 \%)$ are graduated. No patient is illiterate. Among control group, maximum patients (12) are in high school category, 2 patients $(6.7 \%)$ are graduated, 1 patient $(3.3 \%)$ is illiterate and 1 patient $(3.3 \%)$ have some education but literate $(\mathrm{p}=0.5)$. Statistically data is not significant.

\section{Occupation}

10 patients (33.3\%) are unskilled, 8 patients (26.7\%) are skilled, 6 patients (20\%) are semiskilled and 1 patient $(3.3 \%)$ is unemployed. Among control group, $11(36.7 \%)$ are semiskilled, $7(23.3 \%)$ are both skilled and unskilled $(p=0.6)$. Statistically data is not significant.

\section{Domicile}

19 patients (63.3\%) and 19 control (63.3\%) are from rural areas. 11 patients (36.7\%) and 11 control (36.7\%) are from urban areas. (Table 4)

\section{Religion}

Out of 30 patients, Hindus constitute 28 (93.3\%). Among control group, Hindus are 27 (90\%). Muslims among patients and control group are $2(6.7 \%)$ and $3(10 \%)$ respectively.

\section{Male Sexual Functioning (CSFQ-14)}

Male sexual functioning components in CSFQ-14 are Desire/Frequency, Desire/Interest, Pleasure, Arousal and Orgasm. Table 1 explains the data and it is statistically significant.

\section{Male Sexual Functioning (IIEF)}

Components of International Index of Erectile Function questionnaire are erectile function, orgasmic function, sexual desire, intercourse satisfaction and overall satisfaction. Table 2 explains the data which is statistically significant. 
Table 1: CSFQ scores in cases and controls

\begin{tabular}{|l|l|l|l|l|l|}
\hline \multirow{2}{*}{ CSFQ } & Control & Depression & p value \\
\cline { 2 - 6 } & Mean & SD & Mean & SD & \\
\hline Desire/ Frequency & 8.43 & 0.82 & 4.56 & 1.0 & $<0.0001^{*}$ \\
\hline Desire/ interest & 12.23 & 1.1 & 5.97 & 1.4 & $<0.0001^{*}$ \\
\hline Pleasure & 4.13 & 0.35 & 2.83 & 0.87 & $<0.0001^{*}$ \\
\hline Arousal & 12.93 & 0.78 & 7.1 & 1.1 & $<0.0001^{*}$ \\
\hline Orgasm & 12.93 & 0.83 & 7.2 & 1.3 & $<0.0001^{*}$ \\
\hline
\end{tabular}

Independent $\mathrm{t}$ test used in the analysis. * significant $(\mathrm{p}<0.05)$

Table 2: IIEF scores in cases and controls

\begin{tabular}{|l|l|l|l|l|l|}
\hline \multirow{2}{*}{ IIEF } & \multicolumn{2}{|l|}{ Control } & \multicolumn{2}{l|}{ Depression } & \multirow{2}{*}{ p value } \\
\cline { 2 - 6 } & Mean & SD & Mean & SD & \\
\hline Erectile Function & 8.4 & 0.8 & 13.6 & 3.6 & $<0.0001^{*}$ \\
\hline Orgasmic Function & 12.2 & 1.1 & 5.7 & 1.1 & $<0.0001^{*}$ \\
\hline Sexual Desire & 4.1 & 0.3 & 5.8 & 0.9 & $<0.0001^{*}$ \\
\hline Intercourse Satisfaction & 12.9 & 0.8 & 5.4 & 1.2 & $<0.0001^{*}$ \\
\hline Overall Satisfaction & 12.9 & 0.9 & 4.7 & 1.1 & $<0.0001^{*}$ \\
\hline
\end{tabular}

Independent $\mathrm{t}$ test used in analysis. * ${ }^{*}$ ignificant $(\mathrm{p}<0.05)$

\section{DISCUSSION}

Comparative studies indicate higher levels of sexual dysfunction in patients with depression than in controls. Although the incidence of specific types of sexual dysfunction varies across studies, loss of sexual desire may be more common than disorders of arousal and orgasm. For example, in one comparative study, changes in libido were significantly more common in patients with depression, but the prevalence of arousal, orgasmic or ejaculatory problems did not differ from controls [24]. In our study, change in sexual functioning questionnaire (CSFQ-14) shows statistically significant results $(\mathrm{p}<0.0001)$ with decreased desire/frequency, desire/interest, arousal, orgasm and pleasure in the depression group when compared with the control group. International Index of Erectile Function (IIEF) scale shows mild to moderate overall satisfaction with decreased orgasmic function and Intercourse satisfaction in the depression group when compared with control group which is statistically significant $(\mathrm{p}<0.0001)$.

\section{Limitations of the study}

1. Major limitation of the study is the small sample size.

2. A larger sample size could have made the results more generalized.

3. Study did not aim in finding antidepressant effect on male sexual functioning. It could have made an impact in patients with depression.

\section{REFERENCES}

1. Lopater S, Westheimer RK. Human sexuality: A psychosocial perspective. Lippincott Williams \& Wilkins; 2002.

2. Kandeel FR, editor. Male sexual dysfunction: pathophysiology and treatment. CRC Press; 2007.

3. Shiri R, Koskimäki J, Tammela TL, Häkkinen J, Auvinen A, Hakama M. Bidirectional relationship between depression and erectile dysfunction. J Urology 2007;177(2):669-73.

4. Makhlouf A, Kparker A, Niederberger CS. Depression and erectile dysfunction. Urol Clin North Am 2007;34(4):565-74.

5. Baldwin DS. Depression and sexual dysfunction. Br Med Bull 2001;57(1):81-99.

6. Casper RC, Redmond DE, Katz MM, Schaffer CB, Davis JM, Koslow SH. Somatic symptoms in primary affective disorder: presence and relationship to the classification of depression. Arch Gen Psychiatry 1985;42(11):1098-104. 
7. Fernandes GV, Dos Santos RR, Soares W, De Lima LG, De Macêdo BS, Da Fonte JE, De Carvalho BS, Coelho SN, Calado AA. The impact of erectile dysfunction on the quality of life of men undergoing hemodialysis and its association with depression. J Sex Med 2010;7(12):4003-10.

8. Kendurkar A, Kaur B. Major depressive disorder, obsessive-compulsive disorder, and generalized anxiety disorder: do the sexual dysfunctions differ? Prim Care Comp J Clin Psychiatry 2008;10(4):299-306.

9. Mourikis I, Antoniou M, Matsouka E, Vousoura E, Tzavara C, Ekizoglou C, Papadimitriou GN, Vaidakis N, Zervas IM. Anxiety and depression among Greek men with primary erectile dysfunction and premature ejaculation. Ann Gen Psychiatry 2015;14(1):34-9.

10. Reynolds III CF, Frank E, Thase ME, Houck PR, Jennings JR, Howell JR, Lilienfeld SO, Kupfer DJ. Assessment of sexual function in depressed, impotent, and healthy men: factor analysis of a Brief Sexual Function Questionnaire for men. Psychiatr Res 1988;24(3):231-50.

11. Roose SP, Glassman AH, Walsh T, Cullen K. Reversible loss of nocturnal penile tumescence during depression: a preliminary report. Neuropsychobiology 1982;8(6):284-8.

12. Devanand DP, Nobler MS, Singer T, Kiersky JE, Turret N, Roose SP, Sackeim HA. Is dysthymia a different disorder in the elderly?. Am J Psychiatry 1994;151(11):1592-9.

13. Blazer D, Hughes DC, George LK. The epidemiology of depression in an elderly community population. Gerontologist 1987;27(3):281-7.

14. Steiger A, Holsboer F, Benkert O. Studies of nocturnal penile tumescence and sleep electroencephalogram in patients with major depression and in normal controls. Acta Psychiatr Scand 1993;87(5):358-63.

15. Araujo AB, Durante R, Feldman HA, Goldstein I, McKinlay JB. The relationship between depressive symptoms and male erectile dysfunction: cross-sectional results from the Massachusetts Male Aging Study. Psychosom Med 1998;60(4):458-65.

16. Fagan PJ, Schmidt Jr CW, Wise TN, Derogatis LR. Sexual dysfunction and dual psychiatric diagnoses. Compr Psychiatry 1988;29(3):278-84.

17. Jonler M, Moon T, Brannan W, Stone NN, Heisey D, Bruskewitz RC. The effect of age, ethnicity and geographical location on impotence and quality of life. Br J Urology 1995;75(5):651-5.

18. Taylor MJ. Strategies for managing antidepressant-induced sexual dysfunction: a review. Curr Psychiatr Rep 2006;8(6):431-6.

19. Laurent SM, Simons AD. Sexual dysfunction in depression and anxiety: conceptualizing sexual dysfunction as part of an internalizing dimension. Clin Psychol Rev 2009;29(7):573-85.

20. Rosen RC, Riley A, Wagner G, Osterloh IH, Kirkpatrick J, Mishra A. The international index of erectile function (IIEF): a multidimensional scale for assessment of erectile dysfunction. Urology 1997;49(6):822-30.

21. Rosen R, Cappelleri JC, Gendrano N3. The International Index of Erectile Function (IIEF): a state-of-thescience review. Int $\mathrm{j}$ Impotence Res 2002;14(4):226-44.

22. Keller A, McGarvey EL, Clayton AH. Reliability and construct validity of the Changes in Sexual Functioning Questionnaire short-form (CSFQ-14). J Sex Marit Ther 2006;32(1):43-52.

23. Bobes J, Gonzalez MP, Bascaran MT, Clayton A, Garcia M, Moros FR, Banus S. Evaluating changes in sexual functioning in depressed patients: sensitivity to change of the CSFQ. J Sex Marit Ther 2002;28(2):93103.

24. Williams K, Reynolds MF. Sexual dysfunction in major depression. CNS Spectr 2006;11(9):19-23.

$* * * * * * * * * * * * * * * * * * * * * * * * * * * * * * * * * * * *$

$$
\begin{gathered}
\text { Acknowledgements - Nil } \\
\text { Conflict of Interest - Nil } \\
\text { Funding - Nil }
\end{gathered}
$$

